\title{
PIVOTS: Service Learning at the Science, Theatre \& Magic Boundary
}

\author{
M.A. Papalaskari ${ }^{1}$, Karen Hess $^{2}$, Debra Kossman ${ }^{3}$, Sue Metzger ${ }^{4}$, Alain Phares ${ }^{5}$, Robert Styer ${ }^{6}$, Connie Titone ${ }^{7}$, \\ Thomas Way ${ }^{8}$, Randy Weinstein ${ }^{9}$, Francis Wunderlich ${ }^{10}$
}

\begin{abstract}
The PIVOTS partnership has developed the Science \& Theatre Magic Program, a service learning summer program of multidisciplinary, magic-themed science exploration. Faculty participants mentor teenagers, who in turn create and stage a day-long adventure that brings younger children from Philadelphia by train to an "American School of Magic." The creation of the magic school gives powerful expression to the youth voice inherent in the service learning paradigm: ownership of the design in the context of meaningful service sparks active learning. The result is a memorable, scienceinspired, interactive educational performance that connects the diverse populations of teens and the children served in an immersive urban and suburban setting. The program makes significant inroads in realizing the PIVOTS ultimate goals of engaging students in highly motivational multidisciplinary STEM programs and activities that promote positive images of STEM professionals and thus attract and retain interest in STEM careers. (www.csc.villanova.edu/ map/pivots/)
\end{abstract}

Index Terms - Service-learning, Creative design experiences, Magical illusion, K-12 initiatives and partnerships, Theatre.

\section{INTRODUCTION}

The Peer Interdisciplinary Volunteer Outreach with Theatre and Science (PIVOTS) partnership addresses the urgent need for highly motivational programs and activities that encourage children, especially underrepresented minorities, to pursue science, technology, engineering, and mathematics (STEM) careers.

This paper describes the educational foundations, goals, approaches, and results from the 2005 Science \& Theatre Magic Program, a service-learning summer day program that integrates STEM and arts education. In this two-week multidisciplinary program, teenagers (scholars, 13-17 year olds) learn, explore, and apply scientific principles in the creation and staging of a fantastic day-long performance/adventure that they then share with younger children (apprentices, ages 6-12). Inspired by the Harry Potter series of books [1], this culminating event during the second week of the program brings apprentices from Philadelphia, by train, to "enroll" in a fictional "American School of Magic," where the scholars act as guides/teachers (and powerful role models), and deliver science-inspired "magic lessons." The program enrolled 14 scholars, and over 100 apprentices (in three groups) who came from economically impoverished inner-city neighborhoods to participate in the magic school for a day during the second week. The program intentionally blurs the distinction between creativity in STEM and creativity in the arts.

\section{Educational Foundations, GoAls, AND APPROACH}

The ultimate goals of the PIVOTS project are to engage students in highly motivational multidisciplinary programs and activities that promote positive images of STEM professionals and thus attract and retain interest in STEM careers. This section provides background on these goals and describes key features of the PIVOTS approach.

\section{Engaged learning in science and engineering principles}

In an inquiry-oriented approach [2, 3, 4], the teacher presents scientific content in a concrete way and designs hands-on activities that give the learner opportunities to be actively engaged, ideally in both a physical and conceptual sense (Figure 1).

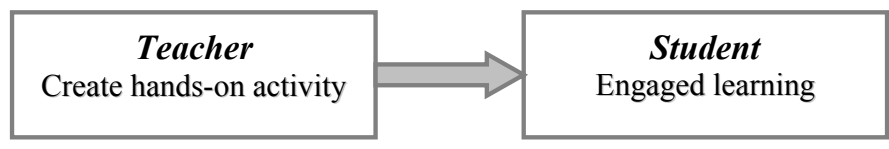

FIGURE 1

INQUIRY BASED TEACHING

This pedagogical practice forms the basis of all inquirybased teaching, where students are expected to become engaged to gain insight into the principles underlying the

\footnotetext{
${ }^{1}$ Mary-Angela Papalaskari, Dept of Computing Sciences, Villanova University, map@villanova.edu

${ }^{2}$ Karen Hess, Science Resources, khess@science-resources.org

${ }^{3}$ Debra Kossman, National Analysts, Inc., dkossman@nationalanalysts.com

${ }^{4}$ Sue Metzger, Director, Office of Part-Time Studies, Villanova University, sue.metzger@villanova.edu

${ }^{5}$ Alain Phares, Dept of Physics, Villanova University, alain.phares@villanova.edu

${ }^{6}$ Robert Styer, Dept of Mathematics, Villanova University, robert.styer@villanova.edu

${ }^{7}$ Connie Titone, Dept of Education and Human Services, Villanova University, connie.titone@villanova.edu

${ }^{8}$ Thomas Way, Dept of Computing Sciences, Villanova University, thomas.way@villanova.edu

${ }^{9}$ Randy Weinstein, Department of Chemical Engineering, Villanova University, randy.weinstein@villanova.edu

${ }^{10}$ Francis Wunderlich, Department of Physics, Villanova University, francis.wunderlich@villanova.edu 
creative presentations offered by the instructor. Despite its demonstrated value, the task of developing effective inquirybased science lessons is very costly, and typically requires a degree of creativity on the part of the educator that far exceeds that elicited from the student. Thus, a need arises to:

- create activities that are flexible and can be readily adapted to a variety of science topics

- $\quad$ assess the impact of lessons or activities

- $\quad$ establish dissemination strategies for successful lessons

The PIVOTS approach for the Science \& Theatre Magic Program is to formulate activities that use the simple, familiar story of a day at the School of Magic as the unifying theme that can be employed to extend and enrich practically any science lesson. This approach takes students behind the scenes and makes them active participants, not only as consumers of creative science experiences, but also as creators (Figure 2).

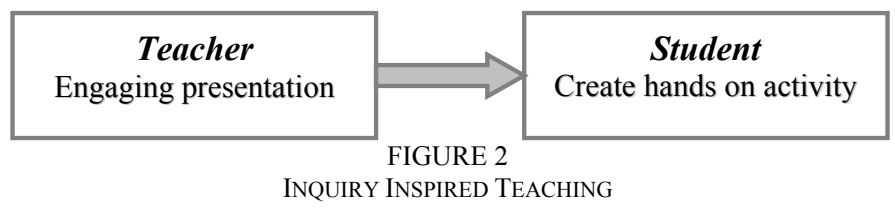

Diverse, positive images of scientists and engineers

Many scientists devote a significant part of their careers to making their fields accessible and attractive to young people. This has resulted in an extensive array of museum exhibits, educational television shows, games, websites, and illustrated books. This obvious creativity does not appear to register, however, when it comes to stereotypes of scientists, where an interest in science often is viewed as antithetical to creativity. For many children, including those already possessing an interest in science, even the most awe inspiring media and displays remain a passive form of entertainment. For many children, this gee whiz approach to science leads to a disengaged, "let's see what else is cool" attitude which merely reinforces the presupposition that science is complex and incomprehensible, a necessary evil.

We need to motivate children to see science, engineering, and mathematics as creative endeavors and as something that they, too, can do. To change attitudes and, especially to attract more women and underrepresented minorities to STEM careers, it is necessary to provide diverse and compelling role models. A recommendation for increasing the participation of women in engineering states:

\begin{abstract}
"Foreground and celebrate a 'broad church' image of engineering, with room for diverse 'types' of people. We must avoid narrowly technicist images of engineering work if we are to attract, and keep, talented people in engineering, by promoting images of engineering work as both technical and social." [5]
\end{abstract}

One way to address this problem is to enlist older children and teens as teachers or mentors for younger children [6]. Successful application of this strategy hinges on the quality of 1-4244-0257-3/06/\$20.00 C 2006 IEEE the initial training of the mentors and even more on the follow up coaching provided (see, for example the work of the Breakthrough Collaborative [7]). The PIVOTS project also uses this approach because it has the effect of modeling excellence and enthusiasm in the subject under study, fostering an interest that can be contagious.

\section{Effective focus for multidisciplinary teaching\& collaboration}

Good developmental settings provide opportunities to acquire a general range of cognitive, physical, psychological, social, and cultural skills [6]. Creating multidisciplinary programs requires a great deal of cooperation and a way to find a common ground - a big challenge for educators. The PIVOTS approach in the Science \& Theatre Magic Program provides a focus for multidisciplinary teaching and collaboration. The unifying theme provided by the story of a day at the School of Magic represents a way to engage students in multidisciplinary science exploration.

\section{Key Features of PIVOTS Programs}

Central features that motivate and inform the Science \& Theatre Magic Program:

(1) Service-learning: Community service provides a way to expose students to the larger context of their education and has demonstrated academic benefits when the service is integrated with traditional instruction $[8,9,10]$. Recent studies suggest that service learning has the potential to motivate students to engage seriously with a variety of subjects, including STEM. At the same time, service learning can respond to a community need: As adolescents progress in age, underprivileged minorities are often left behind because of their lack of access to enrichment activities during the summer and after school $[11,12,13]$. On the community level, the demand for quality enrichment activities to supplement neighborhood summer programs, after-school, and latchkey programs is very clear. For example, the Philadelphia Department of Recreation alone runs over 140 low-cost summer camps in the region; children enrolled in these and other camps around the city can benefit from opportunities to visit and take part in an educational program (for example, as the apprentices in the magic school) on a university campus, an experience that could have a dramatic influence on their futures.

(2) Integration of STEM with Theatre and the Creative Arts: As already mentioned, good developmental settings provide opportunities to acquire a general range of skills. Programs that focus too specifically on only one of these areas leave a need for development in the remaining areas. There is substantial evidence that children learn better through direct involvement and hands-on activities that engage many modalities and all of their senses [14]. Drama, storytelling and re-enactment have proved to be powerful forces in education, have a long tradition of successful application to motivate learners and to clarify difficult concepts in humanities education and can have a profound effect in the teaching of science [15].

October 28 - 31, 2006, San Diego, CA

\section{$36^{\text {th }}$ ASEE/IEEE Frontiers in Education Conference}


(3) Magic as a focus: Magic has been found to be a successful technique to engage students and introduce difficult science concepts from a diverse range of subjects, including Physics [16], Chemistry [17], Computer Science [18, 19], Mathematics [20], and for many years as a successful method for improving learning outcomes [21, 22], and for students to learn through teaching others [23]. One of the reasons for the success of magic in education is that it often leads to a perceived discrepancy between observation and firmly held beliefs, a teachable moment, which is an effective way to motivate children [14]. By choosing a magic trick that relies on a scientific principle, the teacher can thus motivate the students to want to learn the science that explains the trick (Figure 3).

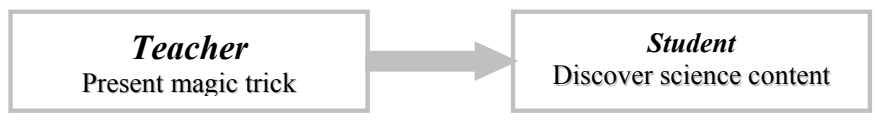

FIGURE 3

MAGIC IN TEACHING

Many excellent collections of science experiments or mathematical games can be used in this manner, such as [24]. PIVOTS seeks to create an effective context for this approach and to also explore the educational benefits of reversing the interplay between magic and science:

\section{The Summer 2005 Science \& Theatre Magic Program}

The Science \& Theatre Magic Program was implemented for the first time in June 10-24, 2005 as a two week day summer camp $(9 \mathrm{am}-4 \mathrm{pm})$. The scholars that attended for the two weeks were selected through an application process, requiring essays describing their background, interest, and ability in science and the creative arts; the application also required the names of two teachers as references. The fourteen scholars enrolled in the summer of 2005 came from many different suburban and urban schools in the Greater Philadelphia region. Only two students knew each other before the start of the program, but the goal of creating the magic school united them immediately. During the second week, three groups of approximately 30-40 apprentices visited the magic school for one day, on three separate days.

The City of Philadelphia Department of Recreation, Cornerstone Academy, and CONGRESO de Latinos (a nonprofit organization that helps Hispanic families) brought groups of children from their summer programs on June 28, June 29 and July 1, respectively.

For the scholars, the first week was devoted to hands-on study of science, theatre arts, magical illusions, and intensive problem-solving sessions where skits based on the science classes were developed and woven into the story of a "School of Magic." Direct instruction occupied the scholars for 15 hours during mornings of the first week. Classes included topics in Physics, Chemistry, Mathematics, Astronomy, Computer Science, Theatre, Native American Culture, and Magical Illusion. By far the most significant form of learning, however, took place during the remainder of the program: (1) the "devising skits" workshops where the scholars made use of what they had studied in their classes to formulate events, lessons, and activities that create the illusion of magic; (2) in the integrating seminars where they invented the stories, props, costumes, banners, musical accompaniment, etc. to support and weave these magical illusions into a coherent event that would engage, challenge, and excite younger children; and, (3) during their actual performance in the School of Magic, where they needed to apply these concepts, act out their characters, to improvise, and to think on their feet.

For example, the scholars created the following method for "sorting" their apprentices into three different "houses" (similar to Harry Potter): They used lenses of different focal lengths to focus light onto different images; the lenses were handed to apprentices as they arrived at the welcoming banquet; the apprentices were sorted into their respective houses by placing their lens into the "sorting apparatus" (a tool created by the scholars, that simply shines light through the lens), the picture on which the light focused determined the apprentice's assigned "house," with whom that apprentice would spend the rest of the day, attending three "magic" lessons. Other ideas originated in chemistry class, which naturally led to a "potions" lesson, but also found their way into the welcoming speech. For example, the iodine clock reaction, which undergoes a very sudden color change at welldefined (but controllable) times was used to cause the headmaster's drink to turn blue, just as he finished his speech. Opportunities for creative expression were abundant and specific talents of the participants easily found their way into the story. For example, one boy led the apprentices across campus playing the bagpipes, another student sewed an extraordinary cape for her costume as the "potions" teacher, and another wrote a poem for the headmaster's welcoming speech.

\section{Teaching the Science Content}

At the Science \& Theatre Magic Program, a uniform approach is used for all the science topics covered: the science topic is presented in a $1 \frac{1}{2}$ hour session in the morning, followed by an unrelated arts or cultural session; in the early afternoon, scholars return to the lab for a "Devising Skits" session where the initial ideas on the morning's topics are collected and debated. In our experience, this unfailingly led to a very heated discussion, a welcome development in a science class! The approach can be outlined as follows:

- Present science topics in a serious manner, emphasizing surprising facts and making occasional allusions to potential playful ways these could be used to misdirect attention, create funny or surprising things or events, or suggest mischievous ways that the topics in question can be applied.

- Following the presentation of a science topic, the students work in small groups to formulate ways that the science concepts presented can be used to create:

$\circ$ an illusion that will allow you to pretend to be teaching your apprentices how to "do magic"; 
- a controllable technique for "sorting" the apprentices into the different "houses" of the magic school, appearing magical or mysterious;

○ the illusion of an "unexpected" event during a lesson or any other part of the drama

- The groups come together to share and discuss the relative merits of the ideas generated under each of these categories

- A list of ideas that have garnered support is created and posted on the students' Internet web log (i.e., "blog").

\section{Integrating Seminars}

Ideas for lessons, sorting, and other events that originated in many units are revisited and compared at the Integrating Seminars, where the concept and drama of the school of magic is developed. When a group of scholars adopts an idea for further development, the scholars in the group take ownership of the idea. The instructor shifts to an advisory role as the students shift to self-directed exploration and deepening of understanding of the chosen topic.

\section{Developing Engineering Skills}

The engineering skills the students practice in this program are aimed at the ABET 2000 criteria [25]. Several of the wellknown (a) to (k) criteria are being introduced to students at an early age. Specifically: (a) applying a knowledge of mathematics, science, and engineering, (c) designing a system to meet desired needs within realistic constraints, (d) functioning on multi-disciplinary teams, (g) communicating effectively, and (i) engaging in life-long learning.

\section{Service Learning}

The scholars in the Science \& Theatre Magic Program engage in service learning by creating an enrichment activity for groups of children drawn primarily from disadvantaged neighborhoods of the city. In Philadelphia these groups consist largely of African American and Hispanic children. The set for this educational adventure/interactive performance spans locations in Philadelphia, public transportation venues (train stations, commuter trains), and the suburban campus of Villanova University. Cultural, religious, and racial issues are raised organically in the course of creating and staging the School of Magic, for example, getting comfortable with public transportation and traveling throughout the city and suburbs, or issues regarding beliefs in magic and the supernatural. Each day that the scholars and apprentices spent together was an intense experience for both age groups of students and for the professor/advisors. It helped them learn a lot about each other and about themselves. Virtually all participants and faculty involved felt united and transformed by the experience.

In the experience of the faculty teaching in the program the School of Magic gives powerful expression to the youth voice inherent in the service-learning paradigm: ownership of the design creates an air of true commitment to the program and to making a difference. Indeed, attendance at the program was nearly $100 \%$ (there was only one absence during the entire two weeks, and that was due to a scholar's attending her cousin's wedding). Furthermore, the focus on creating a magic school and the particular content of the adventure motivated students to engage seriously with science.

\section{The Use of Magic}

The success of magic in the classroom hinges on the ability of the teacher to employ the magic trick in such a way as to (a) elicit curiosity; (b) articulate the connection with the topic under study; and (c) provide a clear and complete explanation in terms of principles. In particular, through this experience, we identified the following pitfalls, which apply primarily to the apprentices in our programs:

- Young children's beliefs in magic or the supernatural can sometimes interfere with eliciting interest in an explanation; worse still, some mistaken beliefs may instead be reinforced, and

- A misunderstanding about the way the world works can lead to misinterpretation of the explanation offered by the teacher. For example, the teacher might begin explaining why it is that the egg "gets sucked into the bottle" in the classic hard-boiled-egg-into-the-milk-bottle experiment and because the child believes that the bottle is empty (does not understand air or air pressure), the explanation offered is taken to be saying instead that the burning flame inside the bottle causes the egg to get hot which somehow raises its pressure and makes it press into the bottle. Once a satisfactory explanation is found, however incorrect, the learner then may not listen to or retain the real explanation offered by the teacher.

For the scholars, the focus on acting, storytelling, with the addition of a unit that specifically teaches principles of Magical Illusion directly confronts the issue of confusion with the supernatural and, if anything, makes participants more discriminating in how they form beliefs. More important still, the model for the interplay between magic and science is reversed (Figure 4):

\begin{tabular}{|c|c|}
\hline Teacher & $\begin{array}{c}\text { Student } \\
\text { Create magic trick }\end{array}$ \\
\hline
\end{tabular}

FIGURE 4

MAGIC IN ACTIVE LEARNING

This process of motivating learning through creative application of science concepts further supports the goal of engaging the scholars in active learning.

\section{Formal ASSESSMENT}

The effectiveness of the Science \& Theatre Magic Program and School of Magic experience was assessed from the perspectives of the youth who participated in them. Dr Debra Kossman (of National Analysts, Inc., a Philadelphia research and consulting firm) designed an exit survey and conducted exit focus groups with scholars during the second week of the program. The survey provided an in-depth examination of whether scholars' experiences were consistent with the

October 28 - 31, 2006, San Diego, CA 
program's goals and what those experiences tell us about the program's achievements, shortcomings, and ultimate promise. Focus groups also were conducted with one group of apprentices one month after they attended the Magic School. The conclusions of this report are summarized in Figure 5 [26]:

The scholars' program provided an intense, stimulating, enjoyable environment for science learning and performance creation, and the Magic School was an exciting, entertaining event for apprentices.

- The Science \& Theatre Magic Program and Magic School clearly succeeded in giving students an experience that they would eagerly pursue again, indeed, provided just the emotionally charged setting that the psychological literature suggests hastens meaningful attitude change [11]. For scholars, the program offered engaging professors and, in particular, peers for whom they felt an unusual affinity.

- It remains to be seen whether the camaraderie that quickly evolved among scholars can be reliability replicated, but it is certainly plausible that students who choose to apply to the program will be self-selected in ways that will unite students with similar or complementary interests and personalities that foster creative, cohesive groups.

- Apprentices would also leap at the chance to attend the Magic School again, but for them, magic and theatre eclipse science as the program's most interesting features.

It is difficult to say whether the program has increased participants' inclination to pursue science or increased their chances of success.

- A majority of the scholars attended the program because they were already interested in science, and the group generally seemed to be comprised of bright, engaged students, not the types of students who require non-traditional teaching methods to reach.

- On the other hand, a few science-wary scholars found the classes interesting and their dim views of their own math and science abilities brightened.

- By contrast, the Magic School apprentices consisted of diverse, underprivileged youth, but few recognized that science was behind the demonstrations, and their views of, and interest in science seemed completely unchanged, especially among the youngest children. If it is necessary that apprentices realize that science lies behind the Magic School for the experience to have the desired effects, then children under the age of about nine may simply be too young to benefit from the program. If merely enjoying the program has a beneficial effect on children's views in the future, then the program could be making progress toward its stated goals.

Reversing the trend away from science careers in the U.S. would seem to require cumulative, repeated attempts from an array of sources. The Science \& Theatre Magic Program may have a difficult time demonstrating empirically that it is reaching its ingoing goals, but it may nonetheless be making a contribution to the cumulative attempts needed to restore the appeal and gratification of science and engineering careers.

FIGURE 5

SUMMARY OF FORMAL ASSESSMENT

\section{CONCLUSIONS AND FUTURE WORK}

We have presented the educational foundations of the PIVOTS project, our experience with the Science \& Theatre Magic Program, and the results from the assessment report of the Summer 2005 program. PIVOTS is using these results to strengthen the program and plan new programs. The assessment plan can be adapted for future use, and some of the data from this first evaluation could form the basis for longitudinal study.

A practical concern shared by faculty and scholars was that the program was too short and did not give them enough time to prepare and to create suitable follow-up materials for the apprentices. In response to these results, the Summer 2006 program has been expanded to three weeks.

The Science \& Theatre Magic Program is also expanding its scope, to include school teachers, who will work with the PIVOTS team to propose courses and service learning opportunities for Villanova University undergraduates who will work with the teachers and their students in their classrooms, after-school programs, or summer programs.

In the Science \& Theatre Magic Program the scholars spend only one day in the School of Magic with each group of apprentices, so it is unrealistic to expect them to impart a significant amount of scientific knowledge and, in any event, the value of such one-time interventions is limited to their effect on attitude change [27]. We thus use peer educators mainly as positive role models and less to deliver content. Given the results of our assessment it seems clear that in future programs the connection with science (a) must be more prevalent, and (b) supported by follow-up activities and resources for the apprentices. Indeed, it is essential to capitalize on the fact that both scholars and apprentices are eager to return, by providing opportunities for continued engagement. Possibilities include programs that turn apprentices into scholars or that expand the experience of the Science \& Theatre Magic Program.

During the Fall and the Spring following the Summer 2005 program, we have experimented with informal gettogethers for the scholars. These events serve no other purpose than to maintain the spirit of collegiality created in the past summer, and to provide the faculty with clues as to how to create programs that will sustain such communities of scholars. It is a testimony to the commitment generated by the Science \& Theatre Magic Program that nearly every scholar chose to take time out of a busy Saturday in order to return for either the Fall or Spring reunion (12 of the 14, with several attending both).

The team of advisors found that the theme of the magic school provides great flexibility and is readily adapted to create activities that promote inquiry in almost any science, engineering, or mathematics subject and to engage students in science exploration and active learning. Moreover, the process of designing the program was very effective in fostering community partnerships and connecting faculty of disparate disciplines in ways that they had never experienced before. The enthusiastic response and unwavering commitment that it generated among the participants (a group that included some purportedly cynical teenagers), was very gratifying to the educators. The project also generated much enthusiasm among city agencies, community groups, and other organizations.

Future plans include an interactive website to serve as a forum and to provide access to educational materials. A television program or a series of commercial-break length television segments in the style of "Mr. Wizard" or "Bill Nye the Science Guy" will be produced in partnership with a local television outlet, to showcase the "magic lessons" and skits developed by children enrolled in PIVOTS programs.

October 28 - 31, 2006, San Diego, CA 


\section{ACKNOWLEDGMENT}

The PIVOTS project comprises faculty, staff, administrators, and students from many departments across Villanova University and associated organizations. The 2005 program was sponsored by the Department of Computing Sciences in partnership with Science Resources (a non-profit organization that disseminates hand-on science activities and resources to K-12 students) and the City of Philadelphia Department of Recreation. Several other departments at Villanova contributed substantial resources, materials, and/or expertise: Physics, Chemistry, Chemical Engineering, Mathematics, Theatre, Part-time Studies, University Information Technologies, Multicultural Affairs, Astronomy, History, and the University Bookstore. Representatives from Southeastern Pennsylvania Transportation Authority (SEPTA) and Amtrak assisted in the transportation plans and logistics at 30th Street Station, Philadelphia. Ideas and support from the following individuals are gratefully acknowledged: Robert Beck, David Cregan, Leonie Elliot-Graves, Robin Hoose, Najib Nadi, Paul Rosier, Joseph Rucker, Rex Saffer, Elvira Stewart, Bryan Wagner, Daphne Weinstein, and Scott Weinstein.

\section{REFERENCES}

[1] Rowlings, J., Harry Potter and the Sorcerer's Stone (and other titles). Scholastic, 1999.

[2] Bransford, J.D., Brown, A.L., Cocking, R.R., How People Learn: Brain, Mind, Experience, and School. National Academy Press, 1999.

[3] Dewey, J., Democracy and Education, Macmillan, 1916.

[4] Mussen, P. H., Conger, J. J., Kagan, J., and Huston, A. C., Child Development and Personality., Harper \&Row, 1984.

[5] Faulkner, W, "Gadget Girls and Boys with their toys: How to attract and keep more women in engineering", ESRC/UKRC, 2006 pp1-4.

[6] Eccles, J and Gootman J. (Eds.) Community Programs to Promote Youth Development. National Research Council, National Academy Press. (2002). Available online: http://www.nap.edu/books/0309072751/html/

[7] Irvine, Matt, "Learning from Both Sides of the Desk: The Summerbridge Program" College Board Review n160 p28-37 1991. See also www.breakthoughcollaborative.org

[8] Crumbaugh, C, Vellom, P., Kline A., and Tsang, E., "Integrating FirstYear Engineering Design And Pre-Service Science Education: A Model for Engineering And Education Collaboration to Enhance K-16 STEM Education", Frontiers in Education, 2004.

[9] Jamieson, L. "Service learning in computer science and engineering", Proceedings of the 33rd SIGCSE technical symposium on Computer science education, 2002, pp133-134.

[10] Marcus, B., Howard, J., King, D, “Integrating Community Service and Classroom Instruction Enhances Learning: Results from an Experiment". Educational Evaluation and Policy Analysis, Vol. 15, No. 4 (Winter, 1993), pp 410-419. American Educational Research Association.

[11] Benson, P., Saito, R., The Scientific Foundations of Youth Development. Minneapolis: Search Institute, 2000.

[12] Cooper H, Charlton K, Valentine JC, Muhlenbruck L., "Making the most of summer school: a meta-analytic and narrative review", Monogr. Soc. Res. Child Dev. 65(1):i-v, pp.1-118, discussion pp.119-27, 2000.

[13] National Institute for Out-of-School Time, Making the Case: A Fact Sheet on Children and Youth in Out-of-School Time. Center for Research on Women, Wellesley College, Wellesley, MA. 2004. Available online: http://www.niost.org/

[14] Ginsburg, H. and Opper, S., Piaget's Theory of Intellectual Development. Prentice Hall, 1969.

[15] Wagner, B., Dorothy Heathcote: Drama as a Learning Medium. Heinemann Drama, 1999.

[16] Ruiz, M. J., "Lenz's Law Magic Trick”, The Physics Teacher 44(2), pp. 96-98, 2006.

[17] Haub, E. K. J., "Disappearing-Reappearing Rabbit Trick: A New Twist to an Old Liquid Nitrogen Demonstration", Chemistry Education, 78(1), p. 46., 2001

[18] Kruse, G., "Magic numbers approach to introducing binary number representation in CSO", ACM SIGCSE Bulletin 35(3), p.272, 2003.

[19] Simonson, S. and Holm, T., "Using a Card Trick to Teach Discrete Mathematics", Primus: Problems, Resources and Issues in Mathematics Undergraduate Studies, v.13, pp.248-269, 2003.

[20] Yew, T. P., "Amazing Mathematical Card Tricks:A Fun Way to Develop Mathematical Thinking, Problem Solving Skills and Creativity", In Proceedings of The Third East Asia Regional Conference on Mathematics Education, Shanghai, China, 2005.

[21] Dean, D. and Dean, P., "Engaging Learners: Magic, Mindmapping, and Mischief meets Understanding By Design”, In Kommers, P., \& Richards, G. (Eds.), Proceedings of World Conference on Educational Multimedia, Hypermedia and Telecommunications, pp. 3031-3034, 2004

[22] Vidler, D. C. and Levine, J., "Curiosity, Magic, and the Teacher" Education, 101(3), pp.273-275, 1981.

[23] Littleton, E. B., "Emerging Cognitive Skills for Writing: Sensitivity to Audience Presence in Five-Through Nine-Year-Olds' Speech", Cognition and Instruction, 16(4), pp. 399-430, 1998.

[24] Gibson, W. B., Magic with Science. Putnam Publishing Group, 1975.

[25] ABET2000 Engineering Accreditation Criteria, available at http://www.abet.org/

[26] Kossman, Debra. Report on the 2005 Science \& Theatre Magic Program (SESAME Magic school program). Unpublished manuscript, 2005.

[27] Fetters, M., \& Vellom, P., "Linking schools and universities in partnerships for change". In LaVoie, D. \& Roth, W-M. (Eds.). Models for Science Teacher Preparation: Bridging the Gap Between Between Research and Practice, Dordrecht, The Netherlands: Kluwer, 2001. 